
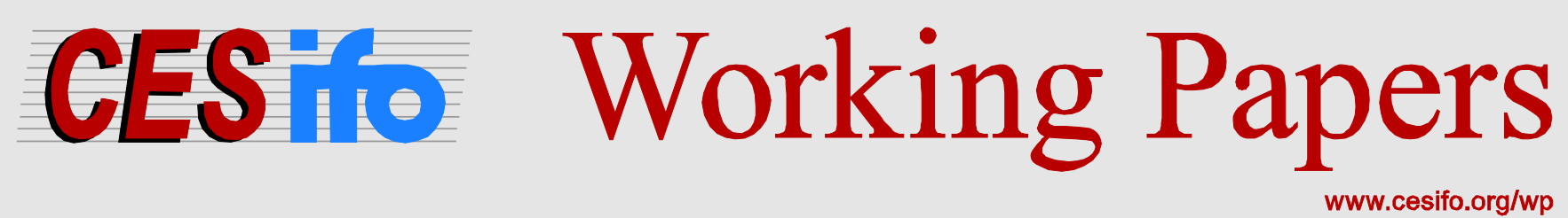

\title{
The Monetary Policy of the ECB: A Robin Hood Approach?
}

\author{
Marcus Drometer \\ Thomas Siemsen \\ Sebastian Watzka
}

\author{
CESIFO WORKING PAPER NO. 4178 \\ CATEgORY 7: MONETARY POLICY AND INTERNATIONAL FinANCE \\ ORIGINAL VERSION: MARCH 2013 \\ THIS VERSION: JUNE 2013
}

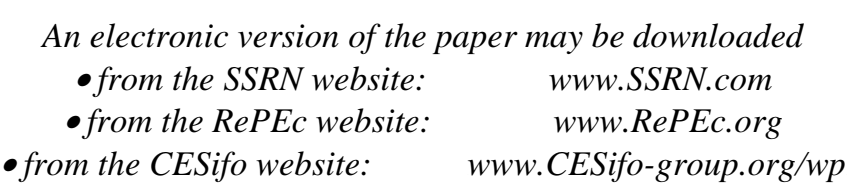




\title{
The Monetary Policy of the ECB: A Robin Hood Approach?
}

\begin{abstract}
We derive counterfactual national interest rate paths for the 17 Euro Area countries for the period 1999 to 2012 to approximate the interest rates countries would have implemented had they still been able to conduct independent monetary policy. We find that prior to the financial crisis the counterfactual interest rates for Germany trace the realized EONIA rate very closely, while monetary policy has been too loose especially for the southern European countries. This situation was inverted with the onset of the financial crisis. To shed light on the underlying decision rule of the ECB, we rank different mechanisms according to their ability to aggregate the national counterfactual paths to the EONIA rate. We find that mechanisms which focus on countries which fare economically worse than the Euro Area average explain the EONIA path best.
\end{abstract}

JEL-Code: E020, E420, E470, E520, E580.

Keywords: decision rule, aggregation rule, counterfactual interest rate path, ECB, Bundesbank.

Marcus Drometer
Ifo Institute - Leibniz Institute
for Economic Research
at the University of Munich
Poschingerstraße 5
Germany-81679 Munich
drometer@ifo.de

Sebastian Watzka

Department of Economics

University of Munich

Ludwigstraße 28

Germany-80539 Munich

Sebastian.Watzka@econ.lmu.de
Thomas Siemsen

Department of Economics

University of Munich

Ludwigstraße 28

Germany - 80539 Munich

Thomas.Siemsen@econ.Imu.de

First Version: December, 2012

This Version: June 20, 2013 
S6 The ECB is obviously in a difficult position. For Germany it would actually have to raise rates slightly at the moment, but for other countries it would have to do even more for more liquidity to be made available [... ]

- German Chancelor Angela Merkel at a German Banking Conference, $25^{\text {th }}$ of April, 2013

\section{Introduction}

After a fairly smooth starting period when the Euro was introduced in January 1999, the ECB has gone through pretty tumultuous years recently. Tensions arose particularly strongly when the financial crisis hit some Euro Area countries and increased unemployment and government bond yields to seemingly ever-higher levels. Some feared the ECB's monetary policy transmission mechanism was broken and the ECB should be taking more aggressive steps; others instead warned that the ECB's prime mandate of price stability might be endangered through more aggressive policy measures and warned against those unconventional measures.

Taking for granted that it is extremely difficult to find out what the optimal monetary policy would look like in the Euro Area, we try to shed light on the ECB's actual decision making. In particular, we ask how the diverging interests of the different Euro Area member countries are considered in the decision process of the Governing Council. Therefore, we first need to find out how national central banks would have set their interest rates if they had still the discretion to do so. We then employ various potential decision rules to aggregate the counterfactual national interest rates and test which resulting interest path fits actual monetary policy in the Euro Area best.

To simulate counterfactual national policy rates for the individual Euro Area countries we employ a Taylor Rule framework. Our simple baseline set of counterfactual paths is derived from a standard Taylor (1993) rule estimated for the Bundesbank for the period 1979 to 1989 . Taylor rules based on the behavior of the Bundesbank are promising when modeling counterfactual national interest rate paths which cater solely to domestic needs for several reasons: First, the Bundesbank had a high degree of independence prior to the introduction of the Euro. Second, the Bundesbank had a very dominant role in Europe and conducted a very successful policy. To test whether our results are robust to the specification of the counterfactual national interest rates paths we consider three alternative specifications: the original rule suggested by John Taylor (Taylor, 1993). As a robustness we account for more sophisticated policy functions and estimate two additional Bundesbank rules which allow for interest rate smoothing and forward-lookingness. 
Our exercise yields various interesting results: We show that prior to the financial crisis the counterfactual interest rate paths for Germany traced the EONIA paths very closely. This was a period when Germany was considered the "weak man of Europe". The contrast is especially striking when compared to the southern European countries and Ireland for which monetary policy has been far too loose. This picture changed with the onset of the financial crisis. While Germany experienced a solid rebound most of the other Euro Area countries remained in economic distress and required now much lower rates than Germany. The ECB seems to have accommodated these needs by keeping the EONIA rate low and closer to the rates required by weak-performing countries than to the rate required in Germany.

We take the latter result as suggestive for the view that next to its key emphasis on independence and price stability, the ECB focuses on the "weakest links" in the Euro Area. To systematically analyze this idea and - more general - to understand how the ECB's Governing Council might have reached its decisions, we test which decision rule aggregates the counterfactual national interest rate paths we derived best to the EONIA path. First, we consider a political economy scenario as in Hayo and Méon (2011) and Riboni and Ruge-Murcia (2010) where the governors follow national interests to account for the possibility that conflicts over monetary policy result in policies against a minority of Euro Area members. Second, we examine a social planner scenario where the Governing Council acts free from national interests and puts special emphasis on countries under unfortunate economic circumstances. We show that such decision rules can explain the actual path of EONIA better than the alternatives hitherto employed in the literature. This suggests that there is more to the decision mechanism than found previously. Depicting the Governing Council Meeting as a bazaar where the members bargain over monetary policy falls short. Rather, the ECB seems to exhibit a social planner perspective catering especially to the needs of the weakest links under its jurisdiction.

We label this the ECB's "Robin Hood" approach, i.e., it is willing to trade-off price stability in booming countries with accommodating the economic needs of countries under distress by fostering aggregate demand there. This might of course - if done systematically - lead to an inflationary bias of monetary policy. However, no such inflationary bias of the ECB's monetary policy has been observed so far and we do not believe that a "Robin Hood" approach of central banking will necessarily lead to such a bias. It might be important to take a somewhat broader view of "price stability" in the sense that asset prices should be watched carefully, too. Thus, it might be argued with the benefit of hindsight that low ECB policy rates did contribute to excessively high housing prices in some regions of the Euro Area. Whilst this argument certainly deserves much more scrutiny, it is beyond the scope of our analysis and we keep it for future research.

Our paper is structured as follows: After briefly discussing the most important literature and our contribution to it, Section 3 derives our counterfactual policy rates for Euro Area member countries. Section 4 then describes the various possible ECB decision rules 
that we compare. Results are shown in Section 5. Section 6 provides three additional sets of counterfactual interest rate paths and various other specifications of "weakness". Finally, Section 7 concludes.

\section{Related Literature}

There exists a large body of literature using counterfactual interest rate paths both for positive and normative analysis. Hayo and Hofmann (2006) compare the ECB's monetary policy stance on inflation and real activity to a Bundesbank counterfactual, estimating a monthly Taylor rule for the period 1979 to 1998. They find that ECB and Bundesbank reacted similarly to inflation while the ECB pursued a somewhat tougher stance on the output gap. While Hayo and Hofmann (2006) are solely concerned with the dichotomy between the ECB and the Bundesbank, our goal is to derive a counterfactual interest rate path for each of the Euro Area member countries and to elaborate on the ECB's decision mechanism.

A large literature has contributed to today's understanding of the Bundesbank's monetary policy. Clarida and Gertler (1997) provide a thorough narrative and empirical analysis of the Bundesbank's spell for the period 1979 to 1993. They conclude that "the estimated coefficient on the output gap variables are very close to the ones Taylor used. Thus, [...], it is not an exaggeration to suggest that the Bundesbank policy rule during post-Bretton Woods era bears reasonable proximity to the rule Taylor employs [...]." This implies that money growth seems not to contribute any explanatory power to the Bundesbank's behavior, a result which is in stark contrast to the official monetary goal published. Gerberding, Seitz, and Worms (2005) show, however, that this result might be driven by the usage of ex-post revised data. Using German real time data money growth enters the regression significantly along inflation and the output gap. Whilst we do not dispute the importance of money growth for the Bundesbank, we follow Clarida and Gertler (1997) and exclude money growth from our specification in order to keep our analysis simple. ${ }^{1}$

A number of studies investigate whether regional factors influence the ECB's decisions. Heinemann and Huefner (2004) derive a policy rule based on Euro Area aggregates with an alternative determined by the median inflation rate and median output gap of all member countries. While regressions based on Taylor rules turn out to be inconclusive, they find some evidence for the influence of regional developments when focusing on actual changes in the interest rate based on an ordered probit approach. Sturm and Wollmershaeuser (2008) investigate the adequacy of the single monetary policy by calculating country-specific monetary stress for the Euro Area countries. For that purpose, they calculate counterfactual scenarios for all member countries based on a Taylor rule calibrated on the ECB and Euro Area aggregates. Among others, they find that business

\footnotetext{
${ }^{1}$ In all our estimation specifications M3 growth enters only insignificantly.
} 
cycles within the Euro Area only converge if more than proportional weight is attached to small member countries when calculation monetary stress for the Euro Area members.

Riboni and Ruge-Murcia (2010) study the interest rate setting of five central banks to understand the decision-making of committees. Among the different voting rules tested in their analysis, a consensus model, where a supermajority is required to change the interest rate, performs best. The main argument behind this result is that such a rule creates a gridlock interval where no changes occur thus producing a high level of persistence of the interest rate. In contrast, with a majority voting rule, the identity of the crucial median committee member and hence the interest rate selected are likely to change from one to another meeting. Yet, Riboni and Ruge-Murcia (2010) abstract from the origins of preference heterogeneity among committee members, i.e. differences in the economic situation of the members of a currency area, which are central to our analysis.

The paper closest to our analysis is Hayo and Méon (2011) who also construct hypothetical interest rate paths based on various estimated Taylor rules. They test different mechanisms to aggregate the resulting country specific optimal policies in order to discover the decision rule of the Governing Council. In contrast to their analysis, we do not restrict ourself to the standard political economy scenarios but also consider decision rule which account for the relative economic situation of the Euro Area countries. Moreover, we extent the time period studied to include the Euro crisis until 2012. Finally, we prefer to calibrate a Taylor rule on the behavior of the Bundesbank and Taylor's original specification instead of averaging different Taylor rules, derived from different estimation procedures. On the one hand, averaging several counterfactual paths leaves ambiguous what the average exactly captures. On the other hand, as discussed below, it is not clear whether the estimation of independent Taylor rules for each of the Euro Area countries is admissible due to limited discretion over monetary policy in some countries.

\section{Derivation of Counterfactual Interest Rate Paths}

As no information on the decisions of the Governing Council are made public, we need to infer its policy rule from the interest rate set by the ECB and observable economic characteristics of the Euro Area member countries. We do so by analyzing different mechanisms which aggregate the national counterfactual rates to the EONIA rate. To this end, we first need to derive counterfactual national interest rate paths for these countries, i.e. the interest rate paths the central bankers would like to set if they could still conduct independent monetary policy.

Several avenues can be used to derive these counterfactual interest rate paths. For example Hayo and Méon (2011) and Hayo (2006) estimate Taylor rules for the pre-ECB period (1979-1998) for each of the Euro Area countries and use the estimated Taylor rule coefficients to expand the national interest rate series beyond 1998. This approach im- 
plicitly assumes that each of the central banks was indeed in the position to conduct an unconstrained monetary policy, adjusting the interest rate level to changes in inflation and the output gap according to national needs. We argue, however, that this assumption might not hold for the central banks of smaller countries during this time. Instead it is rather undisputed in the literature that the Bundesbank played the dominant role in setting the monetary policy stance in continental Europe and that most central banks closely followed the Bundesbank's lead, adjusting their policy rates quid pro quo with the German. ${ }^{2}$ An example worth mentioning is the ERM crisis that resulted from Bundesbank tightening after German reunification (Clarida, Gali, and Gertler, 1998). A further piece of evidence is provided in Table 3.1 which shows the correlation for the money market rate between Germany and the six largest Euro Area countries. Especially for the small neighboring countries, the money market rates show a very strong correlation with the German Frankfurt day-to-day rate.

Table 3.1: Correlations in Euro Area Countries

\begin{tabular}{lc}
\hline $\begin{array}{l}\text { Correlation between } \\
\text { Germany and }\end{array}$ & Money Market Rate \\
\hline \hline Austria & 0.97 \\
Netherlands & 0.96 \\
Belgium & 0.89 \\
France & 0.78 \\
Italy & 0.63 \\
Spain & 0.59 \\
\hline
\end{tabular}

Notes: all correlations are for the period 19801998. Source: IMF IFS

Thus, it is not clear whether the observable national interest rate paths where indeed steered by a catering to domestic needs, i.e. inflation and output gap, and could therefore readily be captured by a Taylor rule, or whether they were simply set in response to exogenous changes in the German monetary policy stance. In that case countryspecific Taylor rule coefficients might not be an adequate measure of a central bank's policy stance and the derivation of the counterfactual interest rate paths. They would not capture a voluntary and systematic central bank response but rather some spurious correlation between exogenous shifts in the policy rate and domestic economic conditions.

Nikolsko-Rzhevskyy and Papell (2011) pursue another path by simply employing Taylor (1993)'s original specification with slight tweaks to the output gap coefficient. By using Taylor's original coefficients they can draw on the notion that this simple rule describes an "optimal", or rather desirable interest path. However, it is not clear whether

\footnotetext{
${ }^{2}$ See for example Clarida, Gali, and Gertler (1998), Sarcinelli (1986), Fischer (1987), Giavazzi and Giovannini (1998), Gros and Thygesen (1988).
} 
these coefficients do indeed describe desirable policy also for the Euro Area. Most European central banks and in particular the German Bundesbank did not follow a dual mandate, targeting both inflation and real activity, but rather had an exclusive focus on price stability. This is suggestive for the notion that the weight put on the output gap would potentially be lower for European central banks compared to the Fed.

For these reasons we follow yet another avenue and take advantage of the Bundesbank's dominant role in determining the monetary policy stance for continental Europe between the 1980-ies and 1998. As mentioned above it is rather undisputed that the Bundesbank conducted an independent and very successful monetary policy during this time spell, to which Gerberding, Seitz, and Worms (2005) refer to as the Bundesbank's most successful period. Keeping our analysis as simple as possible, we estimate a quarterly Taylor rule for the Bundesbank using the period 1979Q3 to 1989Q4. ${ }^{3}$ The estimated coefficients are then used to derive a counterfactual interest rate path for each of the up to 17 Euro Area countries for the period 1999 to 2012.

Of course, it is not certain that these simple counterfactual interest rate paths do indeed capture the monetary policy each Euro Area country would like to implement if monetary policy would still be under national reign. Thus, in Section 6 we repeat our exercise with three alternative sets of counterfactual paths: one using Taylor (1993)'s original specification and coefficients and one using Taylor's specification augmented with an interest-rate smoothing motive. A large body of literature has shown, that on the one hand interest rate smoothing is theoretically desirable and on the other hand empirically observable (for a comprehensive survey see Sack and Wieland, 2000). ${ }^{4}$ Last but not least, we choose a forward looking Taylor rule specification where the Bundesbank sets today's policy rate taking into account inflation expectations one year ahead. This specification also allows for interest rate smoothing. We show that our results are robust to the set of counterfactual national interest rate paths.

We estimate the following equation using ordinary least squares

$$
i_{t}^{B u B a}=\alpha+\beta \cdot \pi_{t}^{G e r}+\gamma \cdot y_{t}^{G e r}+\eta_{t}
$$

where $\pi_{t}^{G e r}$ is the year-on-year growth rate of GDP deflator, $y_{t}^{G e r}$ is the percentage deviation of real GDP from a linear trend and $\eta_{t}$ is an error term. Table 3.2 shows the regression results.

\footnotetext{
${ }^{3}$ This period starts after the second oil price shock had faded off and ends prior to German reunification (see also Clarida, Gali, and Gertler, 1998).

${ }^{4}$ Rudebusch (2002) has shown that interest rate smoothing between quarters is not supported by empirical evidence. Therefore, we choose a monthly specification for this slightly more sophisticated counterfactual interest rate path.
} 
Table 3.2: Bundesbank regression results

\begin{tabular}{cc}
\hline $\begin{array}{c}\text { Dependent Variable: } \\
\text { Sample: }\end{array}$ & $\begin{array}{c}\text { Frankfurt day-to-day rate } \\
\text { 1979Q3-1989Q4 }\end{array}$ \\
\hline \hline$\alpha$ & 3.96 \\
& $(0.91)$ \\
$\beta$ & 1.20 \\
& $(0.21)$ \\
$\gamma$ & 0.59 \\
& $(0.18)$ \\
\hline$R^{2}$ & 0.70 \\
\hline
\end{tabular}

Notes: Standard errors in parenthesis. $N=41$ observations.

All variables enter highly significant into our regression. The inflation coefficient satisfies the Taylor principle. Compared to the results found by Taylor (1993) for the Fed, the Bundesbank put relatively more weight on stabilizing real activity. This is in line with Clarida, Gali, and Gertler (1998). Given that the average communicated inflation target of the Bundesbank between 1979 and 1989 has been $2.9 \%$ this implies a steady state real rate of about $4.5 .^{5}$

Armed with these coefficients we can now return to the derivation of the counterfactual national interest rate paths. In our specification the Bundesbank sets interest rates according to

$$
\begin{aligned}
i_{t}^{B u B a} & =r^{\star}+\pi_{t}^{G e r}+\mu \cdot\left(\pi_{t}^{G e r}-\pi^{\star}\right)+\gamma \cdot y_{t}^{G e r} \\
& =\left[r^{\star}-\mu \pi^{\star}\right]+(1+\mu) \cdot \pi_{t}^{G e r}+\gamma \cdot y_{t}^{G e r} \\
& =\alpha+\beta \cdot \pi_{t}^{G e r}+\gamma \cdot y_{t}^{G e r}
\end{aligned}
$$

and hence the constant $\alpha$ is given by

$$
\alpha=r^{\star}-\mu \pi^{\star}
$$

with $r^{\star}$ being the equilibrium real rate in Germany between 1979 and 1989 and $\pi^{\star}$ being the Bundesbank's inflation target. Projecting the Bundesbank's policy stance into the time period 1999 to 2012 we have to account for potential changes in these structural parameters. Consider the inflation target first. The time period 1999-2012 stood completely under the reign of the ECB. Hence, the inflation target $\pi^{\star}$ is the same for all Euro Area countries and we set it to $2 \%$.

Being aware that measuring the natural real rate is a daunting task we follow Taylor (1993) for the approximation of $r^{\star}$. Taylor (1993) justified choosing a constant of $2-$ $0.5 \pi^{\star}$ since the "2-percent 'equilibrium' real rate is close to the assumed steady state [real]

\footnotetext{
${ }^{5}$ The average inflation target is taken from Clarida and Gertler (1997), Table 10.1
} 
growth rate of 2.2 percent." Therefore, we approximate the equilibrium real rate $r^{\star}$ with the average growth rate of real GDP between 1999 and 2012 in each of the Euro Area countries. ${ }^{6}$ Thereby, we assume that $r^{\star}$ has been constant for the period 1999-2012 but different across Euro Area countries to account for potential differences technology and propensities to save. ${ }^{7}$ We obtain a constant $\alpha^{c}, c \in[1, \ldots, 17]$ which now allows us to derive our baseline counterfactual national interest rate paths $\left\{i_{t}^{c}\right\}$ as

$$
i_{t}^{c}=\alpha^{c}+1.20 \cdot \pi_{t}^{c}+0.59 \cdot y_{t}^{c}, \forall c \in\{1, \ldots, 17\}
$$

Figure 3.1 shows the counterfactual interest rate paths for 6 of the 17 Euro Area countries. $^{8}$

\footnotetext{
${ }^{6}$ Source OECD MEI.

${ }^{7}$ To make sure that our results are not driven by the exact adjustment of the constant we perform the following robustness checks: first we assume the natural real rate to be homogeneous across time and countries. Therefore, we approximate $r^{\star}$ be the average real growth rate in the Euro Area between 1999 and 2012. Second, we account for a downward trend in the natural real rate while keeping the homogeneity assumption across countries. That is, we approximate $r^{\star}$ be the average real growth rate of the Euro Area from 1999 to 2007 and from 2008 to 2012. Third, we allow the natural real rate to vary between countries and across time. Therefore, we take the average real growth rate of a country from 1999 to 2007 and from 2008 to 2012 as proxy for the natural real rate. All our results are robust to these various adjustments. Also, when modeling time variation as a three year rolling window instead of a break in 2008 our results remain robust.

${ }^{8}$ See Appendix A for all 17 countries.
} 
Figure 3.1: EONIA and counterfactual Bundesbank path

Germany

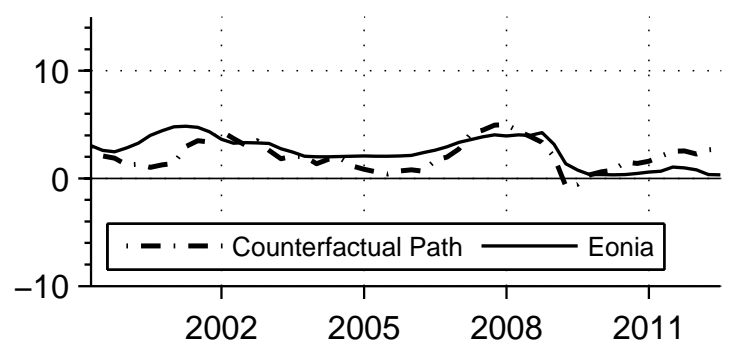

Spain

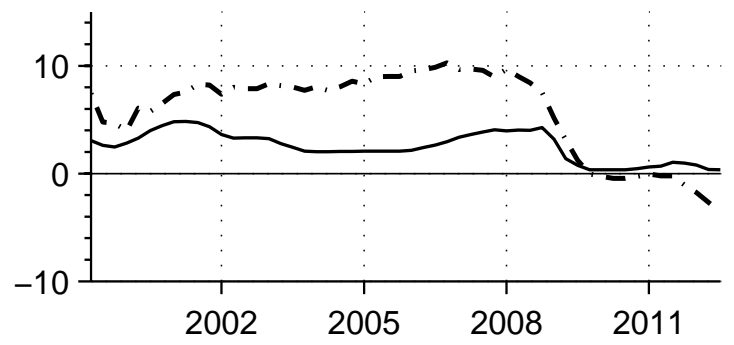

Ireland

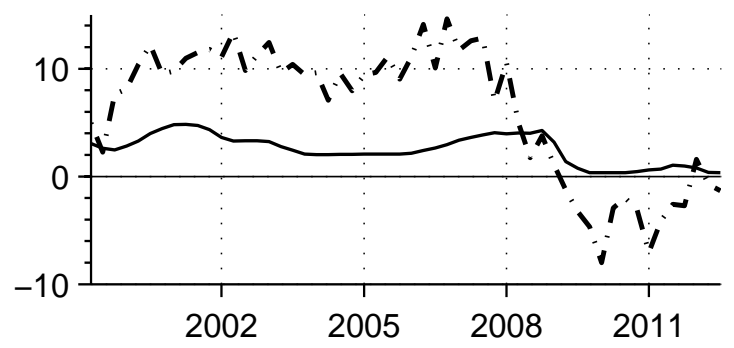

France

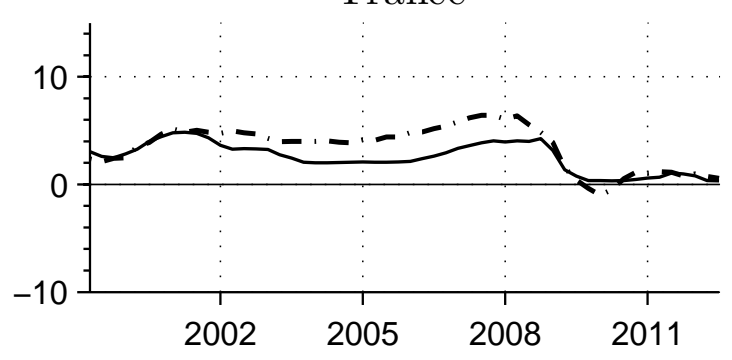

Italy

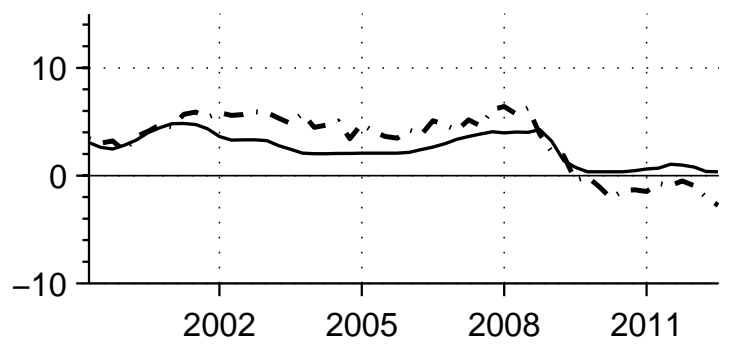

Greece

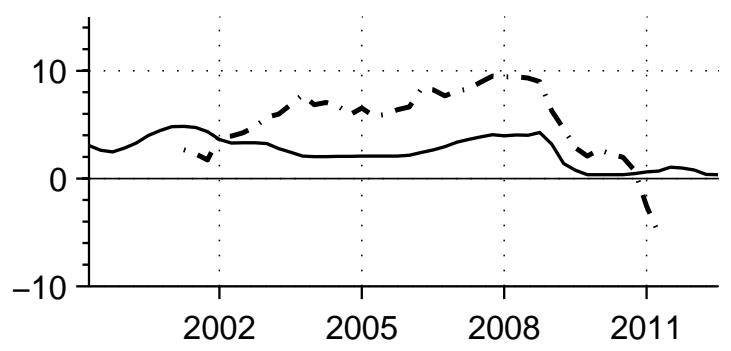

Compared to the other 16 Euro Area countries we find the counterfactual path for Germany being strikingly close to the EONIA rate, especially for the period 2002-2010. This might be suggestive for the view that during this period the ECB had a focus on the economic conditions in Germany, at this time considered as the sick man of Europe. The tight relationship between the counterfactual interest rate paths for Germany and the EONIA rate becomes especially evident if one compares the figure for Germany with those of the other large Euro countries. For all of these countries the counterfactual paths lie above the EONIA rate, suggesting that monetary policy has been too loose from a national point of view for those economies. For southern European countries like Greece, Spain and Italy, but also for Ireland the deviation has been significant, being sometimes an order of magnitude higher than in Germany. Most strikingly is the case of Ireland. At the height of the Irish boom our counterfactual measure would have prescribed an interest rate of up to 15 percentage points. This is mostly driven by the steep price increases of above $4 \%$ in 2007-2008. ${ }^{9}$

\footnotetext{
${ }^{9}$ In the case of Greece Eurostat does not feature data on the GDP deflator beyond 2011Q2.
} 
The overall picture changes with the onset of the Euro crisis. For most of the southern European countries which were hit strongly by rising refinancing costs the counterfactual paths dip deep into negative territory. In Germany, however, the strong economic rebound with prices increasing around $1 \%$ and a robust positive output gap required a monetary tightening already at the beginning of 2010. This time, however, the ECB did not accommodate the German needs. The EONIA rate remained closely at the zero lower bound while the counterfactual German path suggests a policy rate of above $2 \%$ in the middle of 2012. This seems supportive for the notion that the ECB ceased focusing on Germany and instead accommodating the needs of the periphery countries, now the sick men of Europe.

Our exercise predicts counterfactual national interest rates deep in the negative range from the onset of the crisis. Since monetary policy is necessarily constrained by the zero lower bound, our results could be seen as evidence for the need to pursue unconventional policy measures like the recently announced Outright Monetary Transactions.

\section{Potential decision rules of the ECB}

The monetary decisions of the ECB are made by its Governing Council, composed of the (currently) seventeen governors of the national central banks and six members appointed by the European Council. The rule according to which the Governing Council acts is far from being obvious as the minutes of meeting are only published with a very long time lag. According to its statutes, decisions are taken by simple majority rule in the Governing Council. ${ }^{10}$ In principle, this allows for the possibility that conflicts over monetary policy result in policies against a minority of Euro Area members. Against this backdrop, some critics have proposed that voting rights should be granted according to each country's capital key. However, the ECB itself emphasizes that decisions follow a census among experts without reference to national interests. ${ }^{11}$ As no information on the decisions of the Governing Council are made public, we need to infer its policy rule from the interest rate set by the ECB and counterfactual national interest rates as derived in the previous section.

Most of the literature on monetary unions assumes that monetary decisions of common central banks are based on union-wide aggregates (see e.g. Alesina and Grilli (1992), Gros and Hefeker (2002) and Sturm and Wollmershaeuser (2008)). Therefore, we use a decision rule based on Euro Area aggregates, i.e. GDP weighted national inflation and output gap, as a starting point. This could represent a situation where the members of the Governing Council jointly maximize an objective function for the entire Euro Area.

\footnotetext{
${ }^{10}$ See Article 10.1 of the "Protocol of the statute of the European System of Central Banks and of the European Central Bank".

${ }^{11}$ The first president of the ECB put it the following: "The members of the Governing Council considers the interests of the Euro as a whole; they do not represent their respective countries." (Duisenberg, 2002).
} 
Our major exercise consists in testing whether any alternative policy rule can explain the actual interest setting behavior of the ECB better than this benchmark. For that purpose, we first consider a political economy scenario where the governors follow national interests. In this "national view" scenario we look at different potential policy rules, in particular, majority vote, bargaining, chairman dominance and consensus as in Hayo and Méon (2011) and Riboni and Ruge-Murcia (2010). Second, we examine a "Robin Hood" scenario where the Governing Council acts free from national interests as a social planner and puts special emphasis on countries under unfortunate economic circumstances. In particular, we test different ways in which the Governing Council might deviate from focusing on pure Euro Area aggregates in order to support these weak countries.

The political economy scenarios are characterized by the assumption that the members of the Governing Council act in the best interest of their own country. ${ }^{12}$ In our setting each country's counterfactual policy is the interest rate based on Taylor rule estimates as described in the previous chapter. In doing so, we implicitly assume that governors do not take into account detrimental effects on other countries and abstract from potential repercussions on their own economy. Since the Governing Council is composed of the governors of the national central banks and the members of the Executive Board, there exist numerous cases depending on the assumption of how the latter behave. For example, they could vote for their own country's interest or in an Euro Area view. As the resulting differences turn out to be qualitatively negligible in our empirical analysis, we restrict attention to the case where only the governors of the national central banks matter, i.e., a pure one-member-one-vote principle.

The most straightforward political economy scenario is majority voting as prescribed by ECB's official rules. Given the single dimension of monetary policy and the singlepeakedness of the country-specific policy preference, the median voter theorem applies. Hence, the outcome of the process can easily be determined as the median of the distribution of the nationally optimal interest rates. Alternatively, the members of the Governing Council might bargain over monetary policy. We depict this possibility by a simple Nash-bargaining model where the outcome is a weighted sum of individually optimal interest rates. In doing so, we assume that each member has the same bargaining weight. ${ }^{13}$ Given the outstanding role of the president of the ECB, one might expect that the Governing Council's decisions are strongly influenced by the chairman country's interests. To account for this possibility we implement an agenda setting rule where the chairman dominates the decision process: The chairman sets the agenda proposing one alternative to the last period's interest rate. Then the committee decides on whether to implement this new proposal or to stick to the previous rate by simple majority vote. His agenda

\footnotetext{
${ }^{12}$ As Riboni and Ruge-Murcia (2010) we assume that individual vote as if they were pivotal.

${ }^{13}$ Of course, large countries like Germany are likely to be more influential than tiny ones like Malta. Therefore, one might also test a version with bargaining weights based on GDP. However, this policy rule is (depending on the calculation of the Euro area aggregates) nearly or fully identical to our benchmark based on Euro Area aggregates.
} 
setting power allows the chairman to influence the decision process ${ }^{14}$ and generates a gridlock in many cases implying an interest rate that prevails at a fixed level for several periods. ${ }^{15}$. Finally, we consider a consensus rule which requires a supermajority for any changes in monetary policy. Riboni and Ruge-Murcia (2010) argue that such a rule best describes the decision-making of monetary committees, mainly because it entails a gridlock interval thus creating persistence of the interest rate over time. Accordingly, in a first stage the committee decides by simple majority whether to decrease or increase the interest rate. In a second stage, a certain supermajority, in our case as in most of the literature: a two-thirds majority, is required to increase/decrease the interest rate incrementally. Otherwise, the status quo prevails. Any further changes are also taken in incremental steps and require a supermajority. As soon as no such majority is willing to change the interest rate any more, the process ends. ${ }^{16}$

Our analysis in Section 3 suggests that the monetary policy stance of the ECB did feature, at least to some extend, a special caring for countries under distress. To test this novel idea we define different policy rules which take into account the economic needs of the Euro Area countries. First, we only look at the country with the lowest optimal interest rates according to our Taylor rule estimates. Second, we derive the average of the three countries with the lowest optimal interest rates. Third, we take into account the lowest rate of the four largest countries. Finally and crucially, we provide a policy rule which takes into account all Euro Area countries, but puts additional weight on those countries that fare worse than the Euro Area average. In that case, we define "weakness" by the deviation of a country's output gap from the Euro Area output gap: the worse the output gap of a country relative to the output gap of the Euro Area, the more weight does a country's counterfactual interest rate obtain. If a country's output gap is smaller or more negative than the Euro Area output gap, we use its GDP weight when calculating the hypothetical Euro Area interest path. All other countries which fare better than the Euro Area receive a weight of zero. This policy rule is much richer than the first three simple rules based on the lowest rate, but still misses many details like the relative economic situation of the different countries. Therefore, we also provide more sophisticated alternatives in the robustness section.

When calculating the counterfactual interest rates for some countries negative interest rates are predicted - especially since the onset of the financial crisis. As negative interest rates express a country's need for lower rates, it makes sense to interpret negative values in the aggregation process as described above. However, when assessing the fit of a decision rule with respect to EONIA negative rates are questionable. The ECB

\footnotetext{
${ }^{14}$ For example, if $i_{\text {median }}^{*}<i_{\text {chairman }}^{*}<i_{\text {status quo }}$ the chairman can simply propose his bliss point which is supported by the median given the alternative of staying with the status quo.

${ }^{15}$ For a detailed discussion see Riboni and Ruge-Murcia (2010)

${ }^{16}$ For a detailed description see Riboni and Ruge-Murcia (2010). Notice that this consensus rule needs to be distinguished from a 'consensus among experts' where the members of the Governing Council jointly maximize an objective function.
} 
may use unconventional measures like quantitative easing as in the current crisis, but the policy rate is very likely to remain strictly positive. Thus, a negative nominal policy rate is not a plausible decision outcome. To capture this restriction when setting interest rates, we also show results with a zero lower bound constraint for the outcome of the aggregation process according to the different decision rules.

\section{Results}

Figure 5.1 shows the interest paths calculated according to the different decision rules analyzed on the basis of the Bundesbank counterfactual scenario for the time period 1999Q1 to 2012Q2. There is substantial variation in how well the results of the different aggregation mechanisms approximate our benchmark EONIA as represented by the solid line.

As in the previous literature, our benchmark based on Euro Area aggregates as well as the political economy rules predict considerably higher interest rates than observable for the time period up to the financial crisis. Not surprisingly, the decision rules focusing on the lowest rates generate negative interest rates from the onset of the financial crisis at the end of 2008. For the prior time period, however, the Robin Hood rules predict values very close to actual interest rates. Overall, eyeballing evidence suggests that these rules perform better than the political economy scenarios. 
Figure 5.1: EONIA and counterfactual Aggregation Mechanisms

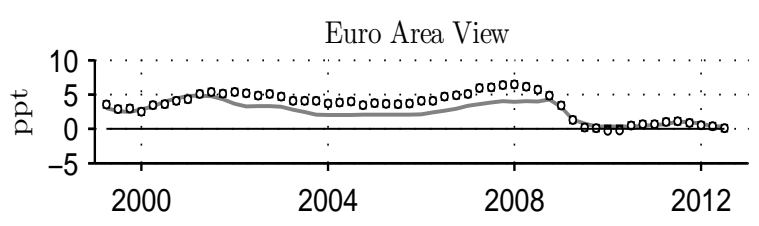

National View
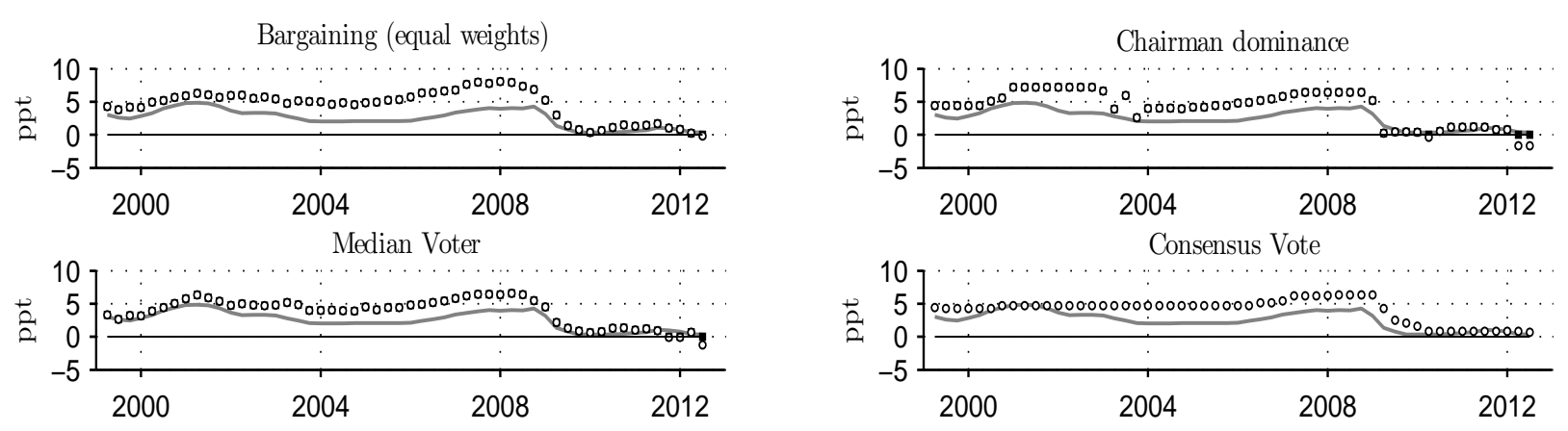

Robin Hood Rules
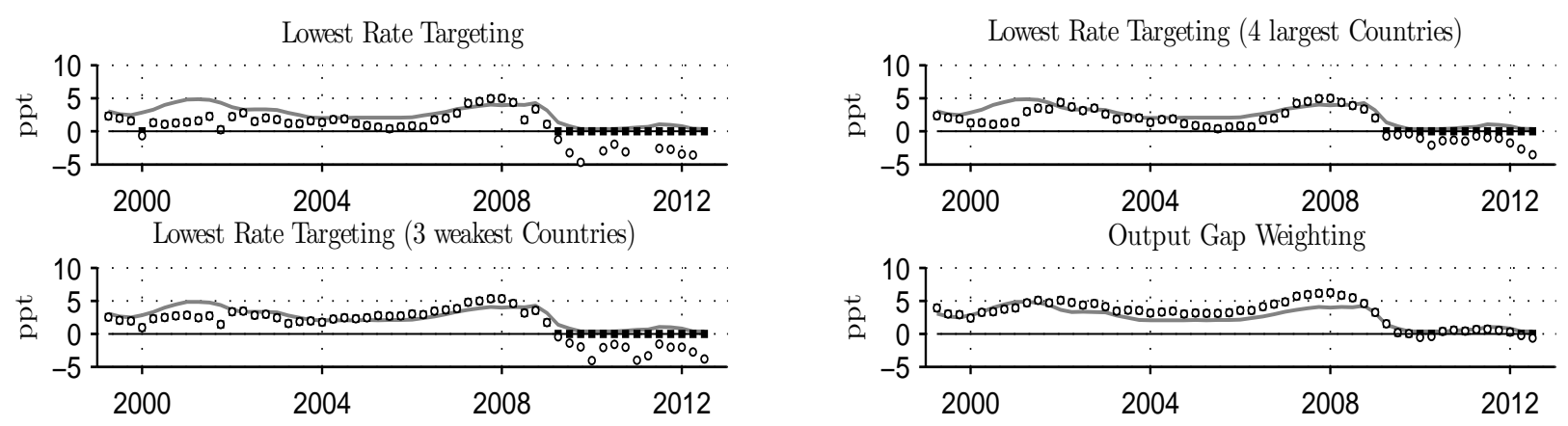

Notes: The solid line indicates the realized EONIA rate. The white circles indicate the result of the respective aggregation mechanism including negative nominal rates. The black squares indicate the aggregation outcome after accounting for the zero lower bound where necessary.

The predicted mean and standard deviation of the different aggregation rules are summarized in Table 5.1. The figures confirm the above presumption: the average interest rate predicted by our benchmark based on Euro Area aggregates and the political economy rules is at least 0.9 percentage points higher than the average EONIA rate. On the other hand, the lowest rate scenarios considerably underestimate the average interest rate, but the decision rule based on the average of the three countries with the lowest optimal interest is closest when considering the zero lower bound constraint. As suggested by Figure 5.1 the Economic Need rule performs well and overestimates the actual average by only 0.6 percentage points. Interestingly, all decision rules show a higher degree 
of variation from the mean as measured by the standard deviation than EONIA.

Table 5.1: Summary statistics 1999Q1-2012Q2

\begin{tabular}{lrcc}
\hline & & Mean & Std. Dev. \\
\hline \hline EONIA & & 2.50 & 1.36 \\
\hline EA aggregates & no ZLB & 3.40 & 1.93 \\
& ZLB & 3.41 & 1.91 \\
\hline \hline Bargaining & no ZLB & 4.53 & 2.29 \\
& ZLB & 4.53 & 2.28 \\
\hline Chairman Dominance & no ZLB & 4.13 & 2.54 \\
& ZLB & 4.20 & 2.40 \\
\hline Median Voter & no ZLB & 3.81 & 2.03 \\
& ZLB & 3.83 & 1.98 \\
\hline Consensus Rule & no ZLB & 4.04 & 1.79 \\
\hline \hline Lowest rate & ZLB & 4.04 & 1.79 \\
\hline Low. Rate (4 largest) & no ZLB & 0.36 & 2.91 \\
& ZLB & 1.39 & 1.35 \\
\hline Low. Rate (average 3) & Zo ZLB & 1.39 & 2.04 \\
& ZLB & 1.75 & 1.53 \\
\hline Outputgap Weighting & no ZLB & 3.09 & 1.90 \\
& ZLB & 3.12 & 1.86 \\
\hline & & & \\
& & & 1.53 \\
\hline
\end{tabular}

The first two moments of time-series only provide very rough measures for the quality of the fit. Therefore, we base our selection on two other criteria: the root mean square error (RMSE) and the mean average error (MAE) of each of the different interest paths with respect to EONIA. Both measures evaluate the distance between actual and predicted interest rates and only differ in the relative weight of deviations. RMSE and MEA are used throughout the literature (e.g. Hayo and Méon, 2011; Riboni and Ruge-Murcia, 2010) as the most natural measures since they do not hinge on any further assumptions. 
Table 5.2: Selection criteria 1999Q1-2012Q2

\begin{tabular}{lrrr}
\hline Benchmark: EONIA & & & \\
Decision rule & & RMSE & MAE \\
\hline \hline \multirow{2}{*}{ EA aggregates } & no ZLB & 1.32 & 1.06 \\
& ZLB & 1.32 & 1.05 \\
\hline \multirow{2}{*}{ Bargaining } & no ZLB & 2.39 & 2.05 \\
& ZLB & 2.39 & 2.05 \\
\hline \multirow{2}{*}{ Chairman Dominance } & no ZLB & 2.14 & 1.87 \\
& ZLB & 2.10 & 1.80 \\
\hline \multirow{2}{*}{ Median Voter } & no ZLB & 1.66 & 1.44 \\
& ZLB & 1.85 & 1.56 \\
\hline \multirow{2}{*}{ Consensus Rule } & no ZLB & 1.85 & 1.56 \\
& ZLB & 1.85 & 1.56 \\
\hline \hline \multirow{2}{*}{ Lowest Rate } & no ZLB & 2.90 & 2.27 \\
& ZLB & 1.54 & 1.24 \\
\hline \multirow{2}{*}{ Low. Rate (4 largest) } & no ZLB & 1.57 & 1.30 \\
& ZLB & 1.18 & 0.93 \\
\hline \multirow{2}{*}{ Low. Rate (average 3) } & no ZLB & 1.86 & 1.45 \\
& ZLB & 1.03 & 0.84 \\
\hline \multirow{2}{*}{ Outputgap Weighting } & no ZLB & 1.08 & 0.90 \\
& ZLB & 1.06 & 0.87 \\
\hline
\end{tabular}

Table 5.2 presents the values of these two selection criteria for each decision rule during the time period 1999Q1 to 2012Q2. When focusing on Euro Area aggregates and the political economy scenarios, it is evident that none of the latter alternatives is able to outperform the simple Bundesbank Taylor rule based on Euro Area aggregates. The political economy rule which performs best is the bargaining based on GDP weights - a finding in line with the analysis of Hayo and Méon (2011). ${ }^{17}$ However, this bargaining rule is only as good as our benchmark based on Euro Area aggregates. Of course, this is not surprising since the calculation of the Euro Area aggregates is basically a GDP weighted average of national interest rates and output gaps. Under a linear policy function both mechanisms are thus roughly identical. This result nicely illustrates the difficulty of inferring a decision rule from observed facts. An average based on GDP weights may well describe actual decision-making of the ECB, but it remains an entirely open question whether this is the result of nationalist governors bargaining in the Governing Council or whether these governors are acting as experts focusing on the Euro Area as a whole without tilting towards the interests of their national government.

The decision rules focusing on the lowest rate of the four largest economies and the average of the three countries requiring the lowest interest rates perform better than our

\footnotetext{
${ }^{17}$ it features the same RMSE and MAE as the EA aggregate mechanism.
} 
benchmark based on euro aggregates when taking into account the zero lower bound constraint. Most importantly, the simple decision rules that only considers those countries that fare worse than the Euro Area average and weighs these countries according to their GDP performs best in terms of all selection criteria and without further adjustments. When taking into account the zero lower bound constraint, the fit becomes even considerably better. All Robin Hood rules perform better than all the political economy scenarios. This finding strongly suggests that the ECB puts special emphasis on the countries that fare economically worse than the Euro Area average in order to stimulate their economies when taking monetary policy decision.

This highlights a willingness of the ECB to trade-off stability concerns in strong economies for growth concerns in economies under distress. We are agnostic about the underlying rationale as we do not observe whether this is the result of increased pressure from the national government or whether the members of the Governing Council jointly maximize such an objective for the Euro Area.

\section{Robustness}

Alternative counterfactual interest rate paths Of course, one might question the assumption of the Bundesbank being the role model for entire continental Europe prior to the Euro introduction. Also, the Taylor rule specification used in Section 3 is rather puristic, being purely static and without interest rate smoothing. To make our analysis robust to these issues we add three additional sets of counterfactual interest rate paths to our analysis. First, we derive a set of counterfactuals following Nikolsko-Rzhevskyy and Papell (2011). In their paper the authors elaborate on the level of the Federal Fund Rate if the zero lower bound would not be binding. Thereby, they employ Taylor (1993)'s original specification, adjusting only the output gap parameter slightly to fit the rule to the stylized fact that the Fed's monetary policy had been "about right" in the early 1990s without doing an explicit estimation. Therefore, using the original Taylor (1993) rule as a counterfactual measure allows us to be agnostic about the specific time period and country where monetary policy can be considered as "successful" by instead drawing on the notion that the Taylor rule incorporates "optimal" monetary policy in general. We derive this set of counterfactual interest rate paths as

$$
i_{t}^{c}=\alpha^{c}+1.5 \cdot \pi_{t}^{c}+0.5 \cdot y_{t}^{c}
$$

where $\pi_{t}^{c}$ is again the year-on-year growth rate of the GDP deflator in Euro Area country $c \in[1, \ldots, 17]$ and $y_{t}^{c}$ is the output gap measured as the percentage deviation of real GDP from a linear trend in country $c$. As for our baseline counterfactual set we adjust the 
constant $\alpha^{c}$ to account for heterogeneity in the equilibrium real rate. ${ }^{18}$

The second alternative set of counterfactual national interest rate paths is a slightly more sophisticated version of our baseline set. As discussed in Section 3 a large body of literature has shown that on the one hand interest rate smoothing is theoretically desirable and on the other hand empirically observable (for a comprehensive survey see Sack and Wieland, 2000). Rudebusch (2002) has shown that interest rate smoothing between quarters is not supported by empirical evidence. Therefore, as a robustness check we estimate a monthly interest-rate-smoothing augmented Taylor rule for the same time horizon as in our baseline scenario (1979M10 to 1989M12). To be more precise we estimate

$$
i_{t}^{B u B a}=\delta \cdot i_{t-1}^{B u B a}+(1-\delta) \cdot\left[\tilde{\alpha}+\tilde{\beta} \cdot \Pi_{t}^{G e r}+\tilde{\gamma} \cdot Y_{t}^{G e r}\right]+\eta_{t}
$$

by ordinary least squares using monthly data on the Frankfurt call rate $\left(i_{t}^{B u B a}\right)$, the annual growth rate of the CPI index $\left(\Pi_{t}^{G e r}\right)$ and an output gap measure $\left(Y_{t}^{G e r}\right)$ derived from regression log industrial production on a linear trend. ${ }^{19} \eta_{t}$ is again an error term. As we will show below, using two different sets of time series for the monthly and for the quarterly estimation leads to slight quantitative deviations between the interest rate paths. The qualitative implications are, however, robust to these two specifications.

Table 6.1: Bundesbank regression results

\begin{tabular}{cc}
\hline $\begin{array}{c}\text { Dependent Variable: } \\
\text { Sample: }\end{array}$ & $\begin{array}{c}\text { Frankfurt day-to-day rate } \\
\text { 1979M10-1989M12 }\end{array}$ \\
\hline \hline$\delta$ & 0.89 \\
& $(0.03)$ \\
$\alpha$ & 2.66 \\
$\tilde{\beta}$ & $(0.60)$ \\
$\tilde{\gamma}$ & 0.74 \\
& $(0.17)$ \\
$R^{2}$ & $(0.59)$ \\
\hline
\end{tabular}

Notes: Standard errors in parenthesis. $N=123$ observations.

Our coefficient for interest smoothing is very close to those reported in Clarida, Gali, and Gertler (1998) (see also Sauer and Sturm, 2003). The inflation coefficient is close to the value of 0.78 reported in Clarida and Gertler (1997). The fact that it does not satisfy the Taylor principle is probably driven by our simple model specification which does not allow for asymmetric central bank reactions. We identify a strong Bundesbank reaction

\footnotetext{
${ }^{18}$ We employ the same constant as for the baseline set. We also find this counterfactual set to be robust to the various exercises explained in footnote 7.

${ }^{19}$ All data was obtained from the Bundesbank.
} 
to deviation of industrial production from trend compared to inflation deviations. Given the $\operatorname{AR}(1)$ specification the $R^{2}$ increases strongly.

With these coefficients at hand we proceed in two steps. First, we adjust the constant to account for heterogeneity in the equilibrium real rate. ${ }^{20}$ Second, we perform a dynamic out-of-sample simulation to derive the smoothed counterfactual interest rate path for each of the 17 Euro Area countries starting at $i_{0}^{c}=\alpha^{c}+\beta \cdot \frac{1}{T} \sum_{T} \Pi_{t}^{c}+\gamma \cdot \frac{1}{T} \sum_{T} Y_{t}^{c}$ with $T$ being the monthly simulation horizon from 1999 to 2012. Thus, our second robustness set of counterfactual national interest rate paths is given by

$$
i_{t}^{c}=0.89 \cdot i_{t-1}^{c}+(1-0.89)\left[\alpha^{c}+0.74 \cdot \Pi_{t}^{c}+1.72 \cdot Y_{t}^{c}\right]
$$

These sets of counterfactual national interest rate paths are exclusively derived from purely backward looking specifications. However, the literature has reached the consensus that central banks when setting policy rates are rather forward looking, taking into account time lags in the policy implication and agents' expectations (see for example Clarida and Gertler, 1997; Clarida, Gali, and Gertler, 1998; Faust, Rogers, and Wright, 2001; Sauer and Sturm, 2003). Thus, for our third robustness set we estimate a 12 month forward looking Taylor rule for the Bundesbank spell 1970M10 to 1989M12 again allowing for interest rate smoothing. We therefore estimate

$$
i_{t}^{B u B a}=\breve{\delta} \cdot i_{t-1}^{B u B a}+(1-\breve{\delta}) \cdot\left[\breve{\alpha}+\breve{\beta} \cdot \mathbb{E}_{t} \Pi_{t+12}^{G e r}+\breve{\gamma} \cdot Y_{t}^{G e r}\right]+\eta_{t}
$$

where $i_{t}^{B u B a}, \Pi_{t}^{G e r}$ and $Y_{t}^{G e r}$ are defined as above. Due to data limitation we use expost revised data instead of real-time data. Rewriting Equation (6.3) making use of the definition for the conditional inflation expectation allows us to write

$$
i_{t}^{B u B a}=\breve{\delta} \cdot i_{t-1}^{B u B a}+(1-\breve{\delta}) \cdot\left[\breve{\alpha}+\breve{\beta} \cdot \Pi_{t+12}^{G e r}+\breve{\gamma} \cdot Y_{t}^{G e r}\right]+\iota_{t}
$$

with $\iota_{t}=(1-\breve{\delta}) \cdot \varepsilon_{t}+\eta_{t}$ and $\varepsilon_{t}=\mathbb{E}_{t}\left[\pi_{t+12}\right]-\pi_{t+12}$. The estimation of a forward looking specification is bound to suffer from endogeneity. We estimate the above equation by GMM using $i_{t-1}^{B u B a}$ to $i_{t-6}^{B u B a}, \Pi_{t-1}^{G e r}$ to $\Pi_{t-6}^{G e r}$ and $Y_{t-1}^{G e r}$ to $Y_{t-6}^{G e r}$ as instruments (see Faust, Rogers, and Wright, 2001, for a similar specification). Table 6.2 shows the results.

\footnotetext{
${ }^{20}$ See footnote 18 .
} 
Table 6.2: Bundesbank GMM regression results

\begin{tabular}{cc}
\hline $\begin{array}{c}\text { Dependent Variable: } \\
\text { Sample: }\end{array}$ & $\begin{array}{c}\text { Frankfurt day-to-day rate } \\
\text { 1979M10-1989M12 }\end{array}$ \\
\hline \hline$\breve{\delta}$ & 0.90 \\
& $(0.03)$ \\
$\breve{\alpha}$ & 2.36 \\
$\breve{\beta}$ & $(0.67)$ \\
$\breve{\gamma}$ & 1.21 \\
& $0.15)$ \\
& 0.31 \\
$R^{2}$ & $(0.14)$ \\
\hline
\end{tabular}

Notes: Standard errors in parenthesis. HAC weighting matrix. Instruments are $i_{t-1}^{B u B a}$ to $i_{t-6}^{B u B a}, \Pi_{t-1}^{G e r}$ to $\Pi_{t-6}^{G e r}$ and $Y_{t-1}^{G e r}$ to $Y_{t-6}^{G e r} . N=123$ observations.

Our results are very close to those summarized in Sauer and Sturm (2003). From here we proceed as before. First, we adjust the constant for each Euro Area country to reflect the heterogeneity in the equilibrium real rates. ${ }^{21}$ Second, we perform an out-of-sample dynamic simulation starting at $i_{0}^{c}=\alpha^{c}+\beta \cdot \frac{1}{T} \sum_{T} \Pi_{t}^{c}+\gamma \cdot \frac{1}{T} \sum_{T} Y_{t}^{c}$ with $T$ being the monthly simulation horizon from 1999Q1 to 2011Q2. ${ }^{22}$ Our fourth set of counterfactual national interest rate paths thus reads

$$
i_{t}^{c}=0.90 \cdot i_{t-1}^{c}+(1-0.90)\left[\breve{\alpha}^{c}+1.21 \cdot \Pi_{t+12}^{c}+0.31 \cdot Y_{t}^{c}\right]
$$

Figure 6.1 shows our four different sets of counterfactual interest rate paths for the same six Euro Area countries. ${ }^{23}$

\footnotetext{
${ }^{21}$ See footnote 18.

${ }^{22}$ Note that compared to the backward looking specification we loose of year of observations.

${ }^{23}$ Appendix A shows the results for all 17 Euro Area countries.
} 
Figure 6.1: EONIA and Counterfactual Interest Rate Paths
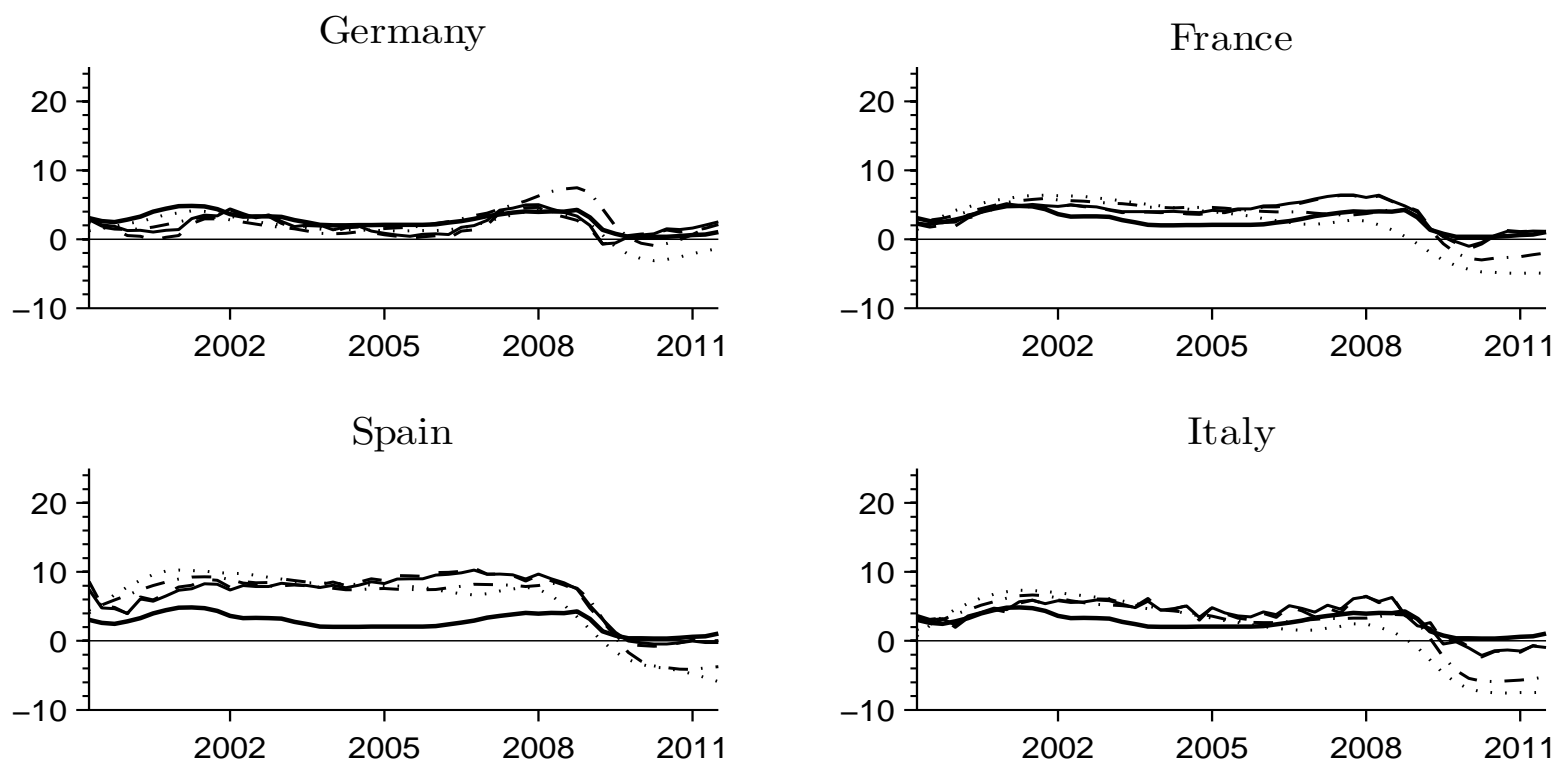

Ireland

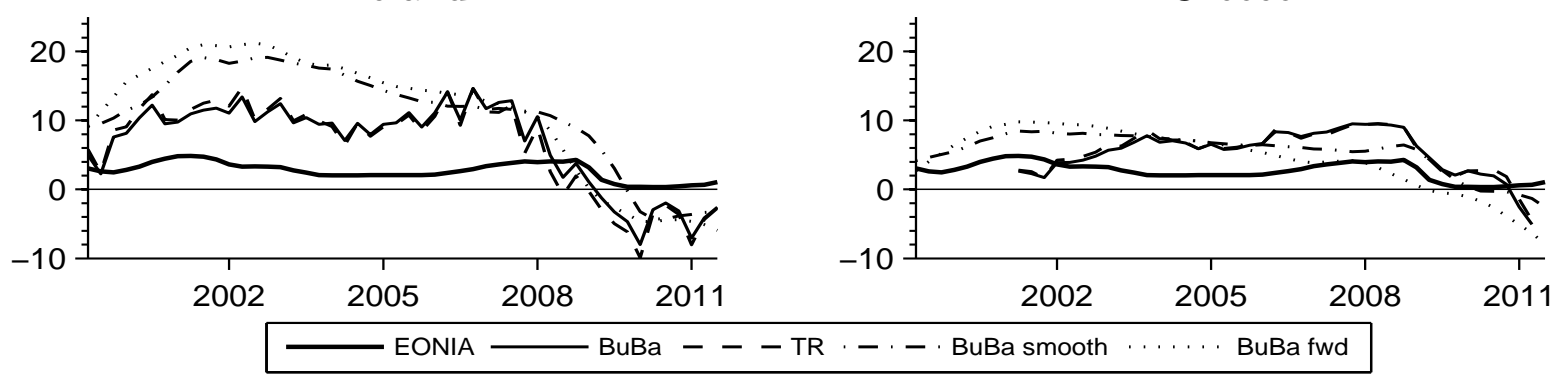

Two results are worth noting. First, the counterfactual interest rate path derived from the original Taylor rule and our baseline counterfactual path (quarterly estimated backward-looking Bundesbank rule) trace each other very closely. In fact, they are hardly distinguishable. The monthly estimated Bundesbank rules with interest rate smoothing (backward-and forward-looking) deviate sometimes considerably from the quarterly paths. As mentioned above this is driven by the usage of two different sets of variables for the quarterly (real GDP and GDP deflator growth) and the monthly (industrial production and CPI growth) counterfactual paths. That said, all four paths yield qualitatively similar results. Thus, we can be confident that the results shown in Section 5 are robust to the consideration of different counterfactual interest rate paths. This will be shown more formally below.

Second, the general picture shown in Figure 3.1 remains. All four counterfactual paths for Germany lie strikingly close to the actual realization of the EONIA rate. Especially for the southern European countries the ECB's monetary policy has been too loose according to all four counterfactuals.

This eyeballing evidence is confirmed by Table 6.3, where we focus for briefness on 
the RMSE only. The results for the MAE are similar. For all four sets of counterfactual national interest rate paths most Robin Hood rules outperform the standard political economy decision rules. Especially the outputgap weighting rule performs exceptionally good across all four specifications.

Table 6.3: Comparison of the different counterfactual measures

\begin{tabular}{lrrccc}
\hline \multirow{2}{*}{$\begin{array}{l}\text { Benchmark: EONIA } \\
\text { Decision Rule }\end{array}$} & & \multicolumn{4}{c}{ RMSE } \\
\cline { 3 - 6 } EA aggregates & BuBa & Taylor & BuBa smooth & BuBa fwd \\
\hline \hline \multirow{2}{*}{ Bargaining } & ZLB & 1.32 & 1.24 & 1.63 & 2.06 \\
& no ZLB & 2.39 & 2.33 & 2.55 & 2.89 \\
\hline \multirow{2}{*}{ Chairman Dominance } & ZLB & 2.39 & 2.33 & 2.51 & 2.64 \\
\hline \multirow{2}{*}{ Median Voter } & ZLB & 2.14 & 2.14 & 1.76 & 2.00 \\
& no ZLB & 1.66 & 1.57 & 2.07 & 2.19 \\
\hline \multirow{2}{*}{ Consensus Rule } & ZLB & 1.65 & 1.56 & 2.07 & 1.84 \\
\hline \hline \multirow{2}{*}{ Lowest rate } & no ZLB & 1.85 & 1.77 & 1.32 & 2.71 \\
& ZLB & 1.85 & 1.77 & 1.32 & 2.71 \\
\hline \multirow{2}{*}{ Low. Rate (4 largest) } & no ZLB & 2.90 & 3.45 & 4.90 & 5.86 \\
& ZLB & 1.54 & 1.89 & 1.75 & 1.87 \\
\hline \multirow{2}{*}{ Low. Rate (average 3) } & ZLB & 1.57 & 1.83 & 3.05 & 3.51 \\
& no ZLB & 1.18 & 1.51 & 1.03 & 1.28 \\
\hline \multirow{2}{*}{ Outputgap Weighting } & ZLB & 1.03 & 2.04 & 3.35 & 4.07 \\
& no ZLB & 1.08 & 0.99 & 1.82 & 2.35 \\
\hline
\end{tabular}

Notes: $B u B a$ indicates our baseline counterfactual set. Taylor indicates the counterfactual set derived from the standard Taylor (1993) specification. BuBa smooth indicates the counterfactual set derived from the monthly estimated Bundesbank policy rule with interest rate smoothing. $B u B a f w d$ indicates the forward-looking policy rate with smoothing. Time period 1999Q1 to 2011Q2.

Alternative measures of economic need Our definition of economic need and the associated weighting scheme is based on the assumption that all countries with a more positive output gap than the Euro Area output gap are neglected in the decision process of the ECB. Of course, the implicit zero weight for these countries is arbitrary and it seems plausible that the ECB takes all member countries into account. Therefore, we introduce a parameter $\alpha$ that determines the relative weight of the countries that fare worse than the entire Euro Area and test whether our results change if less weight is put on these countries. If $\alpha=0$ all countries are weighted according to their GDP as in the baseline scenario, as $\alpha$ increases more emphasis is put on the countries in economic need and for $\alpha \rightarrow+\infty$ we converge to the economic needs rule as defined in the previous 
sections.

As indicated in Table 6.4, the outputgap weighting rule outperforms the baseline rule based on Euro Area aggregates for all possible values of $\alpha$. While the parameter value of the best fit depends on the scenario chosen, adjusting the relative weight of the countries in economic need can improve the fit considerably. This is also the case in the "BuBa smooth" and "BuBa fwd" scenarios, where the outputgap weighting rules approximate EONIA better than the baseline rule for a broad range of parameter values even without taking into account the zero lower bound constraint.

Finally, we provide a more sophisticated weighting scheme that arises naturally if one is concerned with ranking the Euro Area countries according to their economic performance. We define it as follows

1. if country gap $<0$ and Euro Area gap $<0$ then

(a) $\mid$ country gap $|>|$ Euro Area gap $\mid \Rightarrow$ Weight $=\mid$ country gap $|+|$ Euro Area gap $\mid$

(b) $\mid$ country gap $|<|$ Euro Area gap $\mid \Rightarrow$ Weight $=\mid$ Euro Area gap $|-|$ country gap $\mid$

2. if country gap $>0$ and Euro Area gap $>0$ then

(a) $\mid$ country gap $|>|$ Euro Area gap $\mid \Rightarrow$ Weight $=0$

(b) $\mid$ country gap $|<|$ Euro Area gap $\mid \Rightarrow$ Weight $=\mid$ Euro Area gap $|-|$ country gap $\mid$

3. country gap $>0$ and Euro Area gap $<0 \Rightarrow$ Weight $=0$

4. if country gap $<0$ and Euro Area gap $>0$ then

(a) $\mid$ country gap $|>|$ Euro Area gap $\mid \Rightarrow$ Weight $=\mid$ country gap $|+|$ Euro Area gap $\mid$

(b) $\mid$ country gap $|<|$ Euro Area gap $\mid \Rightarrow$ Weight $=\mid$ Euro Area gap $|-|$ country gap $\mid$

Consider the first case. If both a given country and the Euro Area as a whole have a negative output gap, a country with a larger negative output gap relative to the Euro Area average will receive a higher weight compared to a country with a lower negative output gap relative to the average. In the second case, if both a country and the Euro Area average perform above trend, only a country with a positive gap smaller than the average will receive a positive weight, since a country with a stronger performance than the average cannot be considered as weak. The same holds for the third case. If the Euro Area as a whole performs weakly but a country grows above trend it cannot be considered as weak and will therefore get a weight of zero. Only a country with performs even worse than the aggregate will be considered. The last case is interpreted as the first. If a country has a negative gap while the aggregate performs above trend countries with a higher negative gap will receive a higher weight.

As shown in Table 6.4, this more sophisticated outputgap measure of economic need ("Outputgap Weighting (alt. weigh.))" confirms our previous results. It generally implies 
about the same fit under BuBa and Taylor counterfactual scenarios but a slightly worse fit under the "BuBa smooth" and "BuBa fwd" specifications. However, also this Robin Hood rule outperforms the political economy decision rules.

Table 6.4: Comparison of the different Robin Hood rules

\begin{tabular}{lrrrrr}
\hline \multirow{2}{*}{$\begin{array}{l}\text { Benchmark: EONIA } \\
\text { Decision rule }\end{array}$} & & \multicolumn{5}{c}{ RMSE } \\
\cline { 3 - 6 } EA aggregates & no ZLB & 1.32 & 1.24 & 1.63 & 2.06 \\
\hline \hline \multirow{2}{*}{ Outputgap Weighting } & ZLB & 1.32 & 1.23 & 1.56 & 2.05 \\
\hline \multirow{2}{*}{ Outputgap Weighting $(\alpha=2)$} & no ZLB & 1.08 & 0.99 & 1.82 & 2.35 \\
& ZLB & 1.06 & 0.97 & 0.73 & 1.26 \\
\hline \multirow{2}{*}{ Outputgap Weighting $(\alpha=5)$} & no ZLB & 0.97 & 0.90 & 1.47 & 2.36 \\
& ZLB & 0.93 & 0.86 & 0.86 & 1.14 \\
\hline \multirow{2}{*}{ Outputgap Weighting $(\alpha=1000)$} & no ZLB & 0.91 & 0.89 & 1.54 & 2.41 \\
& ZLB & 0.82 & 0.82 & 0.71 & 1.03 \\
\hline \hline \multirow{2}{*}{ Outputgap Weighting $($ alt. weigh.) } & ZLB & 1.10 & 1.18 & 1.81 & 2.59 \\
& no ZLB & 0.91 & 1.05 & 0.73 & 1.06 \\
\hline
\end{tabular}

Notes: $B u B a$ indicates our baseline counterfactual set. Taylor indicates the counterfactual set derived from the standard Taylor (1993) specification. BuBa smooth indicates the counterfactual set derived from the monthly estimated Bundesbank policy rule with interest rate smoothing. $B u B a$ fwd indicates the forward-looking policy rate with smoothing. Time period 1999Q1 to 2011Q2.

\section{Conclusion}

In this paper we elaborated on the decision mechanism of the ECB's Governing Council. Therefore in the first step, we derived a set, and some robust alternatives, of counterfactual national interest rate paths for the period 1999-2012. These paths were derived from a Bundesbank benchmark and proxy the policy stance each Euro Area country would have liked to implement if monetary policy was still under national discretion. In the second step we analyzed various aggregation mechanisms as proxies for the Governing Council's decision process.

The results we derived were twofold: First we found the EONIA rate to trace the counterfactual interest rate path for Germany closely in the period 1999-2007. This suggests a strong focus of monetary policy on German needs. This changed with the onset of the financial crises. Our results show that the ECB seems to have shifted focus to these countries which were hit strongly by the crises. We took this finding as suggestive for the view that the ECB is especially considerate towards the needs of the weakest countries under its jurisdiction. Second and as a new contribution to the literature we 
extended the set of usually considered aggregation mechanisms to include "Robin Hood" rules, rules in which the Governing Council has a special focus on economically weak countries. We showed that these decision mechanisms perform better than national view scenarios such as bargaining.

Obviously, our proposed measures are open to debate and nobody will ever know what counterfactual interest rates might in fact have prevailed. With this qualification in mind our analysis suggests that there is more to the decision mechanism than found in the previous literature. Depicting the Governing Council Meeting as a bazaar where the members bargain over monetary policy falls short. Rather, the ECB seems to exhibit a social planner perspective catering especially to the needs of the weakest links under its jurisdiction. Whilst in this paper we refrain from assessing such a policy normatively, we believe its implications are important for public and especially policy debate. An endeavor which is left for future research. 


\section{References}

Alesina, A., ANd V. Grilli (1992): “The European Central Bank: Reshaping Monetary Politics in Europe," in Establishing a Central Bank: Issues in Europe and Lessons from the US, ed. by V. G. a. P. M. M. Canzoneri. Camebridge Univerity Press, Camebridge.

Clarida, R., J. Gali, and M. Gertler (1998): “Monetary policy in practice - Some international evidence," European Economic Review, 42, 1033-1067.

Clarida, R., and M. Gertler (1997): "How the Bundesbank conducts Monetary Policy," in Reducing Inflation: Motivation and Strategy, ed. by C. Romer, and D. Romer. University of Chicago Press.

Duisenberg, W. (2002): "Some remarks on the euro in a US context," Speech at a breakfast meeting of the Council of Foreign Relations, New York, 19 April (www.ecb.int.).

Faust, J., J. Rogers, and J. Wright (2001): “An empirical comparison of Bundesbank and ECB monetary policy," Board of Governors of the Federal Reserve System: Internation Finance Discussion Papers, (705).

Fischer, S. (1987): "International Macroeconomic Policy Coordination," NBER Working paper, 2233.

Gerberding, C., F. Seitz, And A. Worms (2005): "How the Bundesbank really conducted monetary policy," The North American Journal of Economics and Finance, 16, 277-292.

Giavazzi, F., And A. Giovannini (1998): "Models of the EMS: Is Europe a Greater Deutschmark Area," in Global Macroeconomics, ed. by R. Bryant, and R. Portes. New York: St. Martin's Press.

Gros, D., and C. Hefeker (2002): "One Size Must Fit All: National Divergence in a Monetary Union," German Economic Review, 3, 247-262.

Gros, D., And N. Thygesen (1988): "Le SME: performances et perspectives," Observations et diagnostiques économiques, 24.

Hayo, B. (2006): "Is European Monetary Policy Approprate for the EMU Member Countries? A Counterfactual Analysis," Marburg Papers on Economics, (10-2006).

Hayo, B., ANd B. Hofmann (2006): “Comparing monetary policy reaction functions," Empirical Economics, 31, 645-662.

Hayo, B., And P.-G. Méon (2011): “Behind closed doors: Revealing the ECB's decision rule," Joint Discussion Paper Series in Economics, (35-2011).

Heinemann, F., and F. P. Huefner (2004): "Is the View from the Eurotower Purely European? - National Divergence and ECB Interest Rate Policy," Scottish Journal of Political Economy, 51, 544-558.

Nikolsko-Rzhevskyy, A., and D. Papell (2011): “Taylor's Rule versus Taylor Rules,” working paper.

Riboni, A., and F. J. Ruge-Murcia (2010): "Monetary Policy by Committee: Consensus, Chairman Dominance, or Simple Majority," Quarterly Journal of Economics, 125, 363-416.

Rudebusch, G. (2002): "Term structure evidence on interest rate smoothing and monetary policy inertia," Journal of Monetary Economics, 49(6), 1161-1187. 
SACK, B., AND V. Wieland (2000): "Interest-rate smoothing and optimal monetary policy: a review of recent empirical evidence," Journal of Economics and Business, 52(1-2), 205-228.

SARCINELli, M. (1986): "The EMS and the International Monetary System: Towards Greater Stability,” Banca Nazionale del Lavoro Quartlery Review, 57(83).

Sauer, S., And J. Sturm (2003): “Using Taylor Rules to Understand ECB Monetary Policy," CESifo Working Paper, (1110).

Sturm, J., and T. Wollmershaeuser (2008): "The Stress of Having a Single Monetary Policy in Europe," CESifo Working Paper, (2251).

TAYlor, J. (1993): "Discretion versus policy rules in practise," Carnegie-Rochester Conference on Public Policy, 39, 195-214. 


\section{A Additional Figures}

Figure A.1: Eonia and counterfactual Bundesbank path
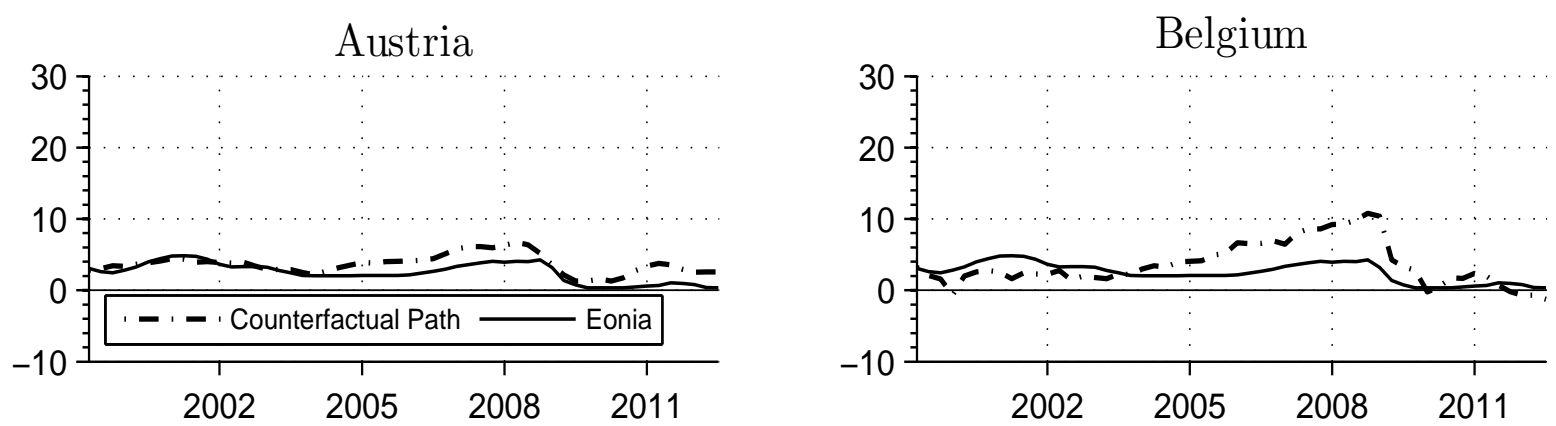

Cyprus
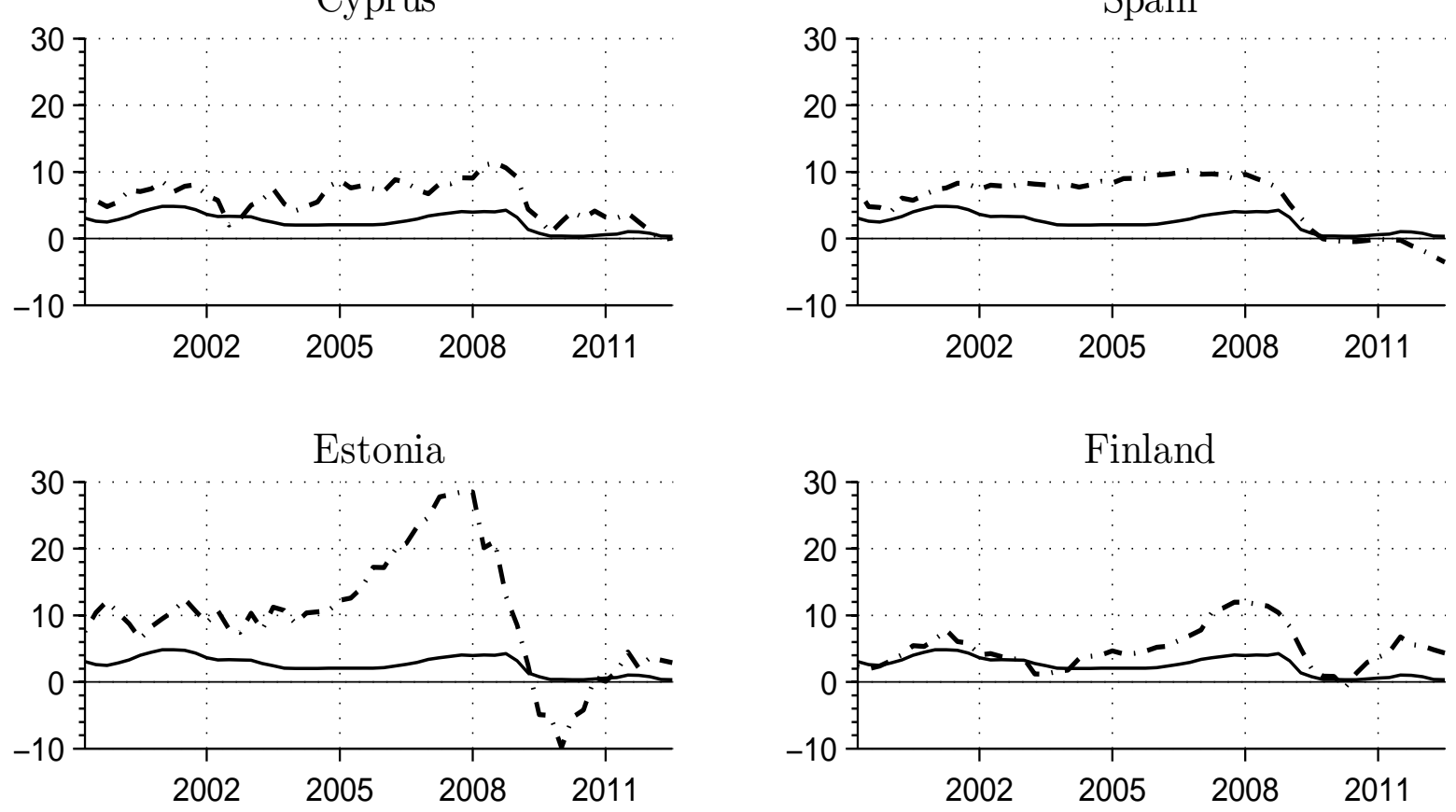
Figure A.2: Eonia and counterfactual Bundesbank path

France

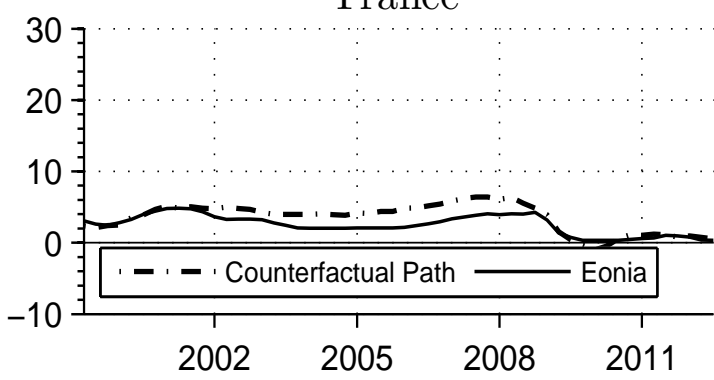

Greece

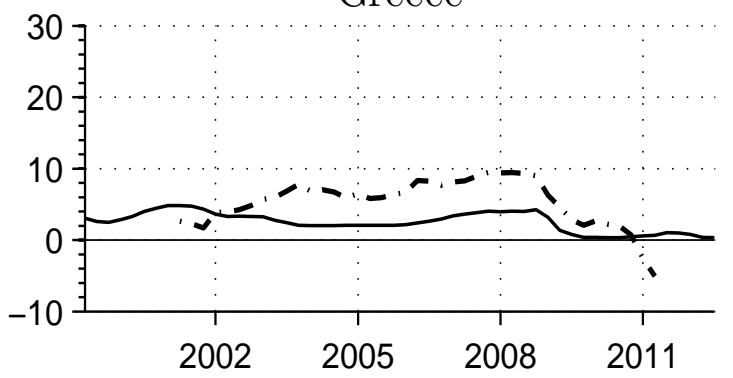

Italy

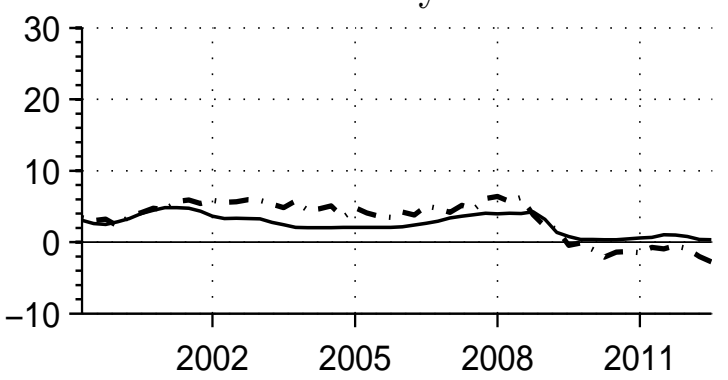

Germany

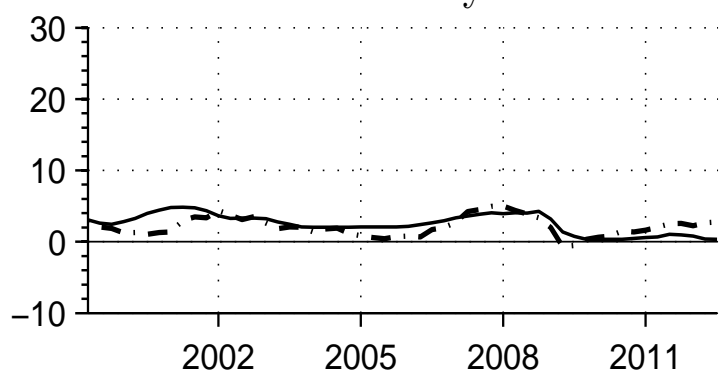

Ireland

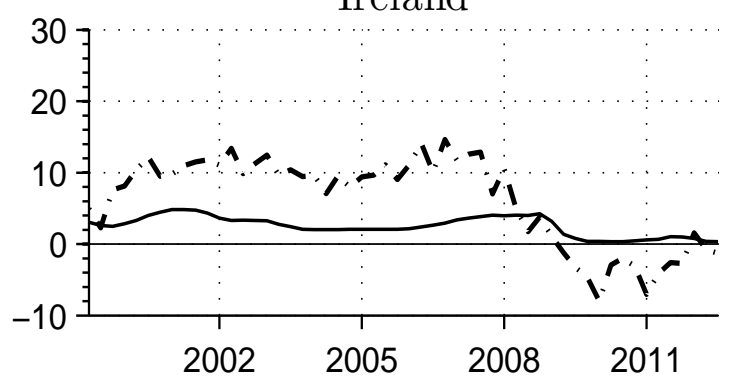

Luxembourg

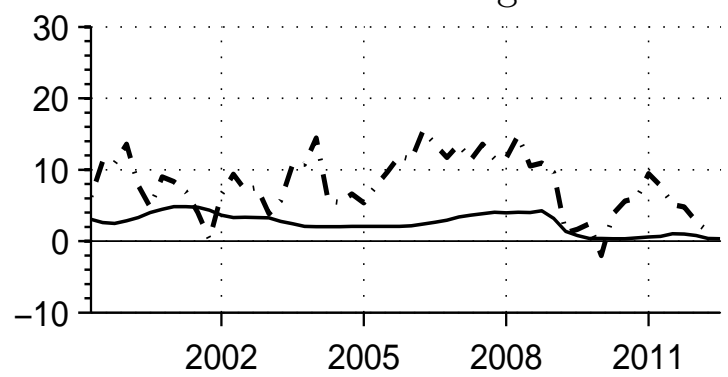


Figure A.3: Eonia and counterfactual Bundesbank path
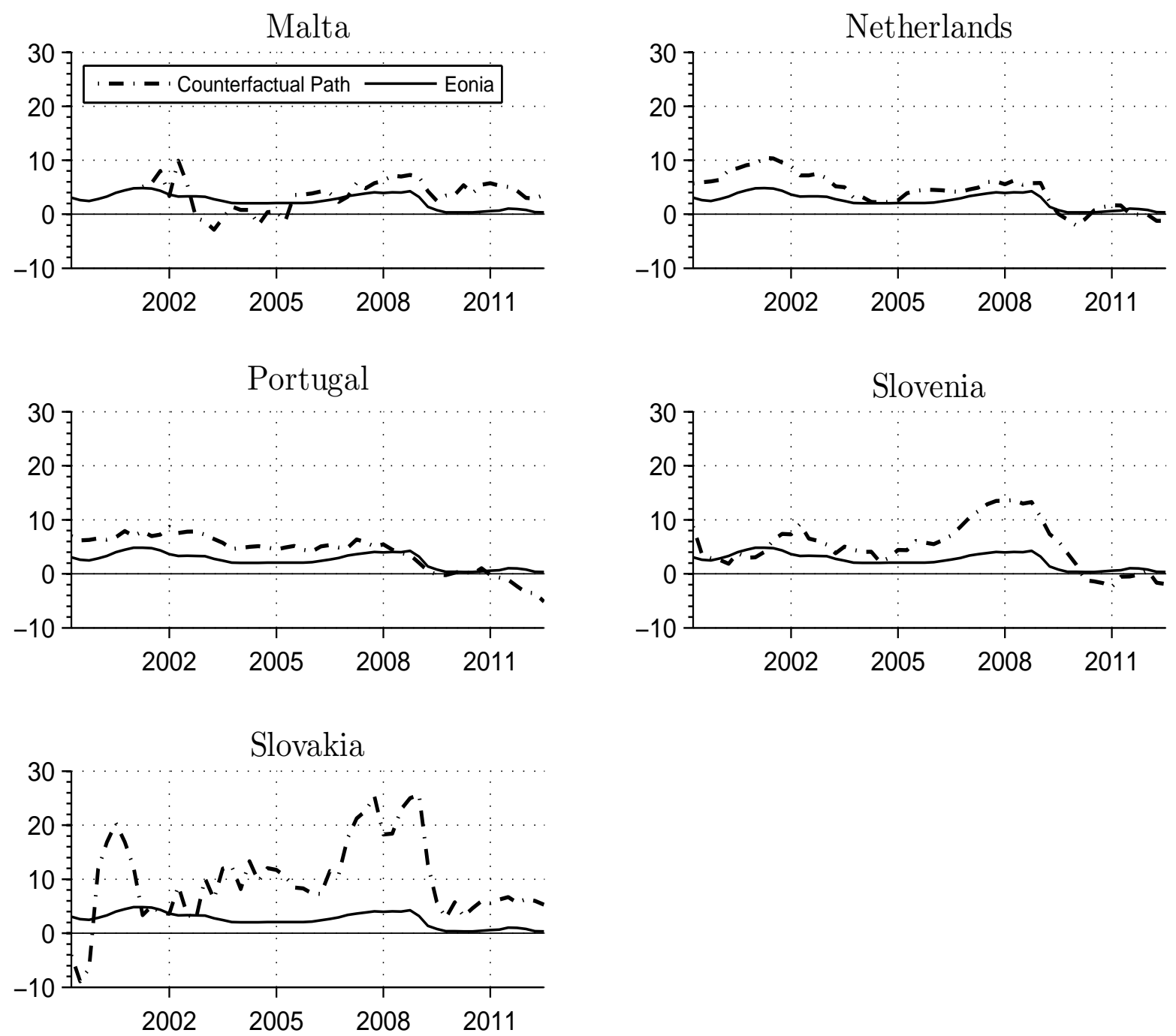
Figure A.4: Counterfactual Measures
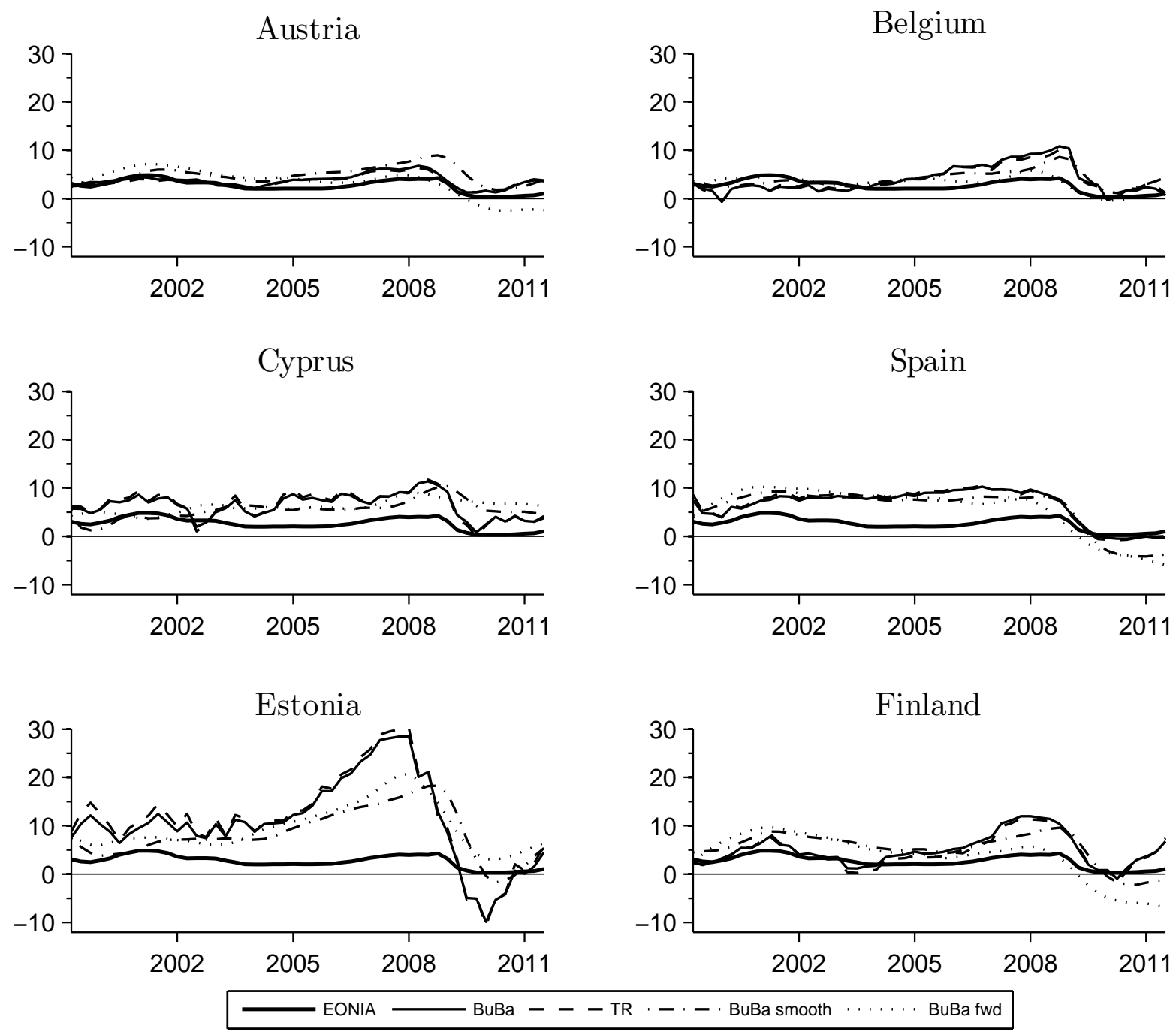
Figure A.5: Counterfactual Measures
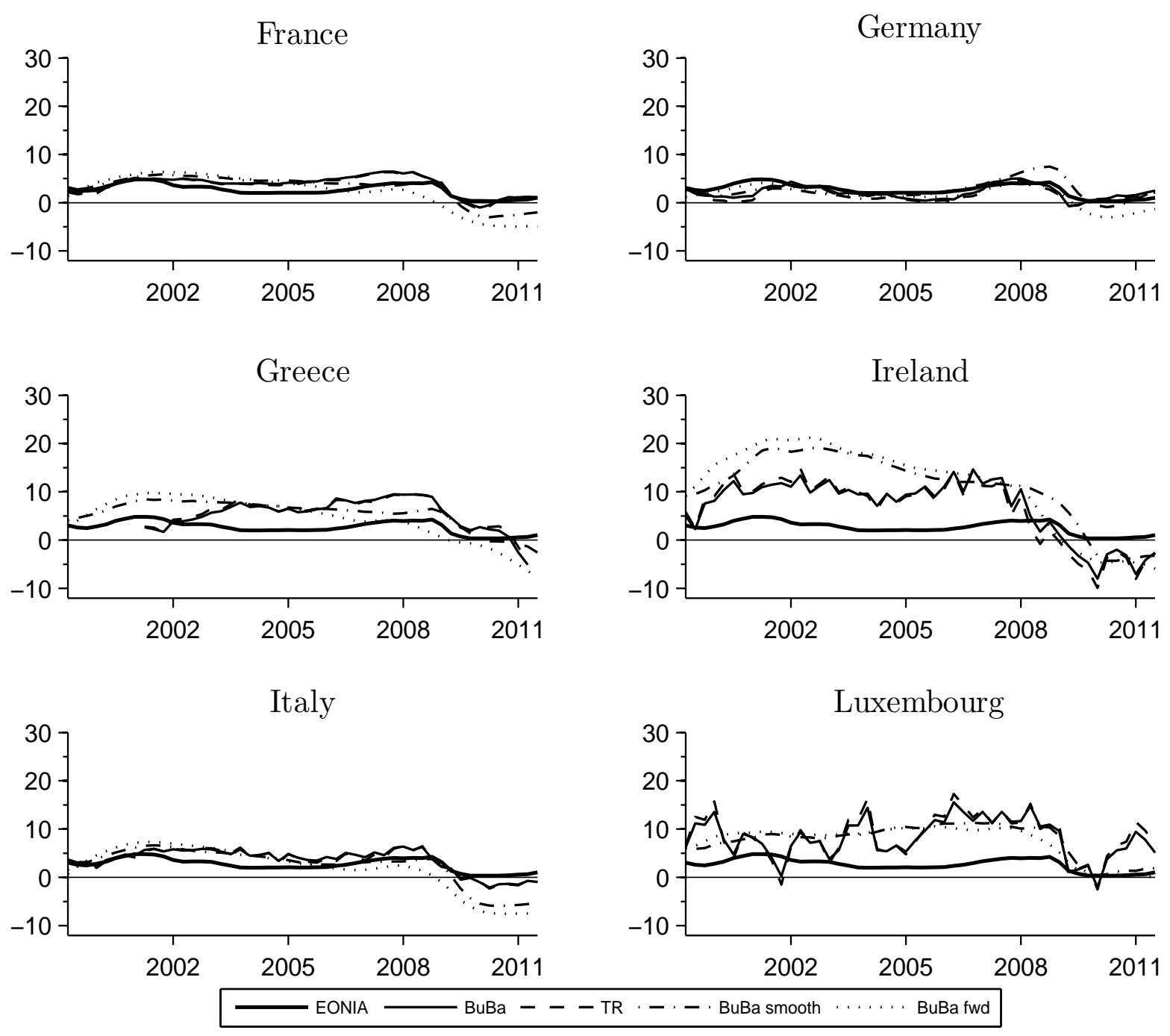
Figure A.6: Counterfactual Measures
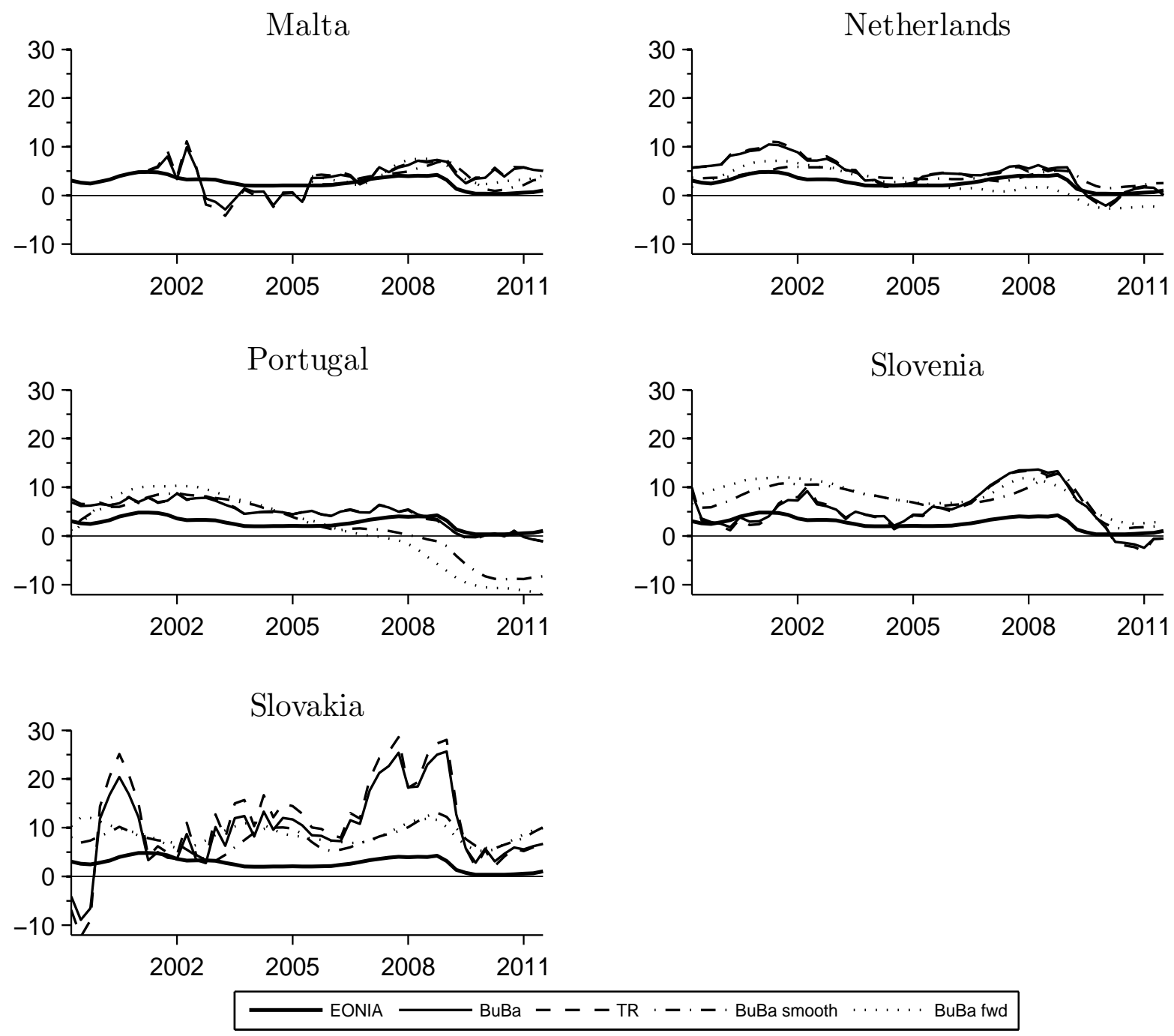